\title{
Regulated protein degradation controls PKA function and cell-type differentiation in Dictyostelium
}

\author{
Sudhasri Mohanty, ${ }^{1}$ Susan Lee, ${ }^{1}$ Nagendra Yadava, ${ }^{1}$ Marian J. Dealy, ${ }^{2}$ Randall S. Johnson, ${ }^{2}$ \\ and Richard A. Firtel ${ }^{1,3}$ \\ ${ }^{1}$ Section of Cell and Developmental Biology and Center for Molecular Genetics, ${ }^{2}$ Section of Molecular Biology, University \\ of California, San Diego, La Jolla, California 92093, USA
}

Cullins function as scaffolds that, along with F-box/WD40-repeat-containing proteins, mediate the ubiquitination of proteins to target them for degradation by the proteasome. We have identified a cullin CulA that is required at several stages during Dictyostelium development. culA null cells are defective in inducing cell-type-specific gene expression and exhibit defects during aggregation, including reduced chemotaxis. PKA is an important regulator of Dictyostelium development. The levels of intracellular cAMP and PKA activity are controlled by the rate of synthesis of cAMP and its degradation by the cAMP-specific phosphodiesterase RegA. We show that overexpression of the PKA catalytic subunit (PKAcat) rescues many of the culA null defects and those of cells lacking FbxA/ChtA, a previously described F-box/WD40-repeat-containing protein, suggesting CulA and FbxA proteins are involved in regulating PKA function. Whereas RegA protein levels drop as the multicellular organism forms in the wild-type strain, they remain high in culA null and $f b x A$ null cells. Although PKA can suppress the culA and $f b \times A$ null developmental phenotypes, it does not suppress the altered RegA degradation, suggesting that PKA lies downstream of RegA, CulA, and FbxA. Finally, we show that CulA, FbxA, and RegA are found in a complex in vivo, and formation of this complex is dependent on the MAP kinase ERK2, which is also required for PKA function. We propose that CulA and FbxA regulate multicellular development by targeting RegA for degradation via a pathway that requires ERK2 function, leading to an increase in cAMP and PKA activity.

[Key Words: Dictyostelium; PKA; differentiation; cullin; protein degradation]

Received December 5, 2000; revised version accepted April 11, 2001.

Regulated protein degradation is an important component of many cellular pathways. This has been shown most elegantly in the timing of the cell cycle, which is controlled in part through the formation and activation of specific cyclin complexes and their subsequent degradation via a pathway that involves ubiquitination and proteolysis (Willems et al. 1996, 1999; Krek 1998; Deshaies 1999; Toda et al. 1999; Tyers and Jorgensen 2000).

Cullins comprise a family of proteins that are a part of the E3 ubiquitin protein ligase complex (Kiproes et al. 1996; Mathias et al. 1996; Feldman et al. 1997; Listzwan et al. 1998; Patton et al. 1998). In Saccharomyces cerevisiae, the cullin Cdc53p interacts with the ubiquitin-conjugated enzyme Cdc34p and phosphorylated cyclin $C \ln 2 p$, whose degradation is required for the $G_{1}-S$ transition during the cell cycle (Mathias et al. 1996; Willems et al. 1996). Cdc53 is also required for ubiquitination of

${ }^{3}$ Corresponding author.

E-MAIL rafirtel@ucsd.edu; FAX (858) 534-7073.

Article and publication are at www.genesdev.org/cgi/doi/10.1101/ $\operatorname{gad} .871101$. the phosphorylated CDK inhibitor Siclp, in which it forms a ubiquitin ligase complex with Skp1 and the Fbox-containing protein Cdc4p (SCF) (Bai et al. 1996; Feldman et al. 1997). A highly homologous complex consisting of an F-box-containing protein, a homolog of SKP1, and a member of the cullin family is necessary in human cells for the $\mathrm{G}_{1}-\mathrm{S}$ transition (Listzwan et al. 1998; Lyapina et al. 1998). These evolutionarily conserved complexes are thought to target specific proteins for ubiquitin-mediated degradation (Krek 1998).

Components of the pathways that control protein ubiquitination are also important for controlling a variety of cellular processes including neuron development and multicellular development in Dictyostelium (Clark et al. 1997; Hegde et al. 1997). In Dictyostelium, a UBC and a UBP (ubiquitin hydrolase or deubiquitinating enzyme) control the temporally and spatially restricted degradation of the MAP kinase kinase kinase (MEK kinase) $\operatorname{MEKK} \alpha$, which regulates developmental timing, cell-fate decisions, and spatial patterning (Chung et al. 1998). Degradation of MEKK $\alpha$ is controlled through an F-box and WD40 repeats, which presumably interact 
with the Dictyostelium Skp1 and a cullin to mediate ubiquitination and degradation of the targeted protein (Feldman et al. 1997; Listzwan et al. 1998; Patton et al. 1998). For some substrates (e.g., the F-box subunit of the SCF E3 ligase and MEKK $\alpha$ ), the targeted protein contains an F-box (Chung et al. 1998; Galan and Peter 1999); in others, an F-box-containing protein forms complexes with the targeted protein to mediate its degradation (Listzwan et al. 1998; Lyapina et al. 1998). Understanding the specificity of these reactions and elucidating the cellular functions controlled by such pathways is essential for determining how targeted protein degradation is used as a regulatory mechanism to control multicellular development in eukaryotes.

Cyclic AMP-dependent protein kinase A (PKA) is an important regulator of development in Dictyostelium, vertebrates, and Drosophila (Reymond et al. 1995; Jiang and Struhl 1996; Perrimon 1996; Hammerschmidt et al. 1997; Heasman 1997; Nusse 1997; Ohlmeyer and Kalderon 1997; Loomis 1998; Aubry and Firtel 1999). In Dictyostelium, PKA is required for aggregation, including the expression of the adenylyl cyclase ACA, cell-type differentiation, and culmination (Mann and Firtel 1991, 1993; Simon et al. 1992; Schulkes and Schaap 1995; Horn and Gross 1996; Zhukovskaya et al. 1996; Mann et al. 1997; Loomis 1998; Shaulsky et al. 1998; Thomason et al. 1998). The level of intracellular cAMP, which determines the level of free catalytic subunit and PKA activity, is controlled by the rate of synthesis of cAMP and its degradation by the cAMP-specific phosphodiesterase RegA, a response regulator and effector of a two-component His kinase regulatory cascade (Shaulsky et al. 1996, 1998; Thomason et al. 1998). The phenotypes of regA null cells, which have elevated cAMP levels (Meima and Schaap 1999) and presumably elevated PKA activity, are similar to those of PKA regulatory subunit (PKA-R) null cells, which have constitutive PKA activity (Simon et al. 1992; Shaulsky et al. 1996, 1998; Thomason et al. 1998). These cells exhibit precocious induction of cell-type-specific genes and spore maturation and have defects in chemotaxis and aggregation (Loomis et al. 1998; Shaulsky et al. 1998; Thomason et al. 1998, 1999b; Wessels et al. 2000). Knockouts of RegA and PKA-R are capable of suppressing a common set of mutations, suggesting they have similar genetic consequences.

We present evidence that regulated protein degradation plays a central role in controlling PKA activity and cell-type specification in Dictyostelium. Our results support a model in which the MAP kinase ERK2 controls the degradation of RegA though an SCF complex containing the cullin CulA and the F-box/WD40-repeat-containing protein $\mathrm{FbxA} / \mathrm{ChtA}$. This work provides new insights into the role of regulated protein degradation in the control of cell and developmental transitions, including those regulating cell-fate decisions.

\section{Results}

Isolation of the culA and fbxA null mutant strains

The $c u l A$ and $f b x A$ null strains were identified in REMI screens for developmental mutants defective in multicellular development. CulA was cloned as described in Materials and Methods. The cloning and preliminary analysis of $f b x A$, also called $\operatorname{cht} A$, has been described previously (Ennis et al. 2000; Nelson et al. 2000). The sequence of the CulA ORF indicates that it is a member of the cullin family of proteins (Fig. 1A; GenBank accession no. AF020287). The highest levels of identity are to murine and human cullin 1 (51\%), Drosophila cullin 1 $(48 \%)$, Caenorhabditis elegans cullin $1(40 \%)$, and Dictyostelium cullin B (40\%). RNA blot analysis shows that CulA encodes a single transcript of $\sim 3.5 \mathrm{~kb}$, which is present at a low level during growth and increases significantly at the onset of development, peaking at $8 \mathrm{~h}$, decreasing slightly, and increasing again during culmination at $20 \mathrm{~h}$ (Fig. 1B). No transcript is found in culA null cells.

culA null cells exhibit aggregation and morphogenesis defects

Wild-type cells form aggregates by $10 \mathrm{~h}$ (Fig. 2A), migrating slugs at $16 \mathrm{~h}$ (Fig. 2B), and mature fruiting bodies by $24 \mathrm{~h}$ (Fig. 2C). culA null cells form large aggregation streams (Fig. 2D) that break up into multiple aggregates and then fuse to form large aggregates (Fig. 2E), which produce multiple tip-like protrusions (Fig. 2F), after which morphogenesis terminates. This terminal structure contains stalk-like vacuolated cells (Fig. 2G), which stain with calcofluor (Fig. 2J), indicating they contain cellulose, and populations of undifferentiated cells that are neither spores nor stalk cells (Fig. 2H), which are probably similar to basal disc cells, as there is no stalktube-like casing around the vacuolated cells [Fig. 2, cf. I (wild-type) with J (culA null)]. No mature, heat- and detergent-resistant spores were observed (data not shown).

Aggregation defects in culA null cells were examined by use of time-lapse video phase contrast microscopy of a monolayer of cells (Ma et al. 1997; Meili et al. 1999). Such analyses visualize cAMP waves propagating through the lawn of cells as changes in cell shape in response to stimulation by the chemoattractant (Rietdorf et al. 1996; Ma et al. 1997). The initial wave patterns of culA null cells are similar to those of wild-type cells. However, at later times, multiple domains partially fuse, leading to the formation of the large, aberrant aggregation streams and aggregates (Fig. 2D; data not shown). In wild-type strains, the mounds initiate a rotary movement, which leads to tip formation after $\sim 1 \mathrm{~h}$ (Rietdorf et al. 1996; Sukumaran et al. 1998; Kellerman and McNally 1999). In contrast, in culA null strains this rotary movement continues for an additional $12 \mathrm{~h}$ and multiple, independent centers form within the large mounds, producing multiple tips as shown in Figure 2F (data not shown).

As this analysis suggested that chemotaxis was delayed in culA null cells, we studied chemotaxis directly by examining the ability of aggregation-competent cells to move toward cAMP emitted from a micropipette (see Materials and Methods). Whereas wild-type cells become 


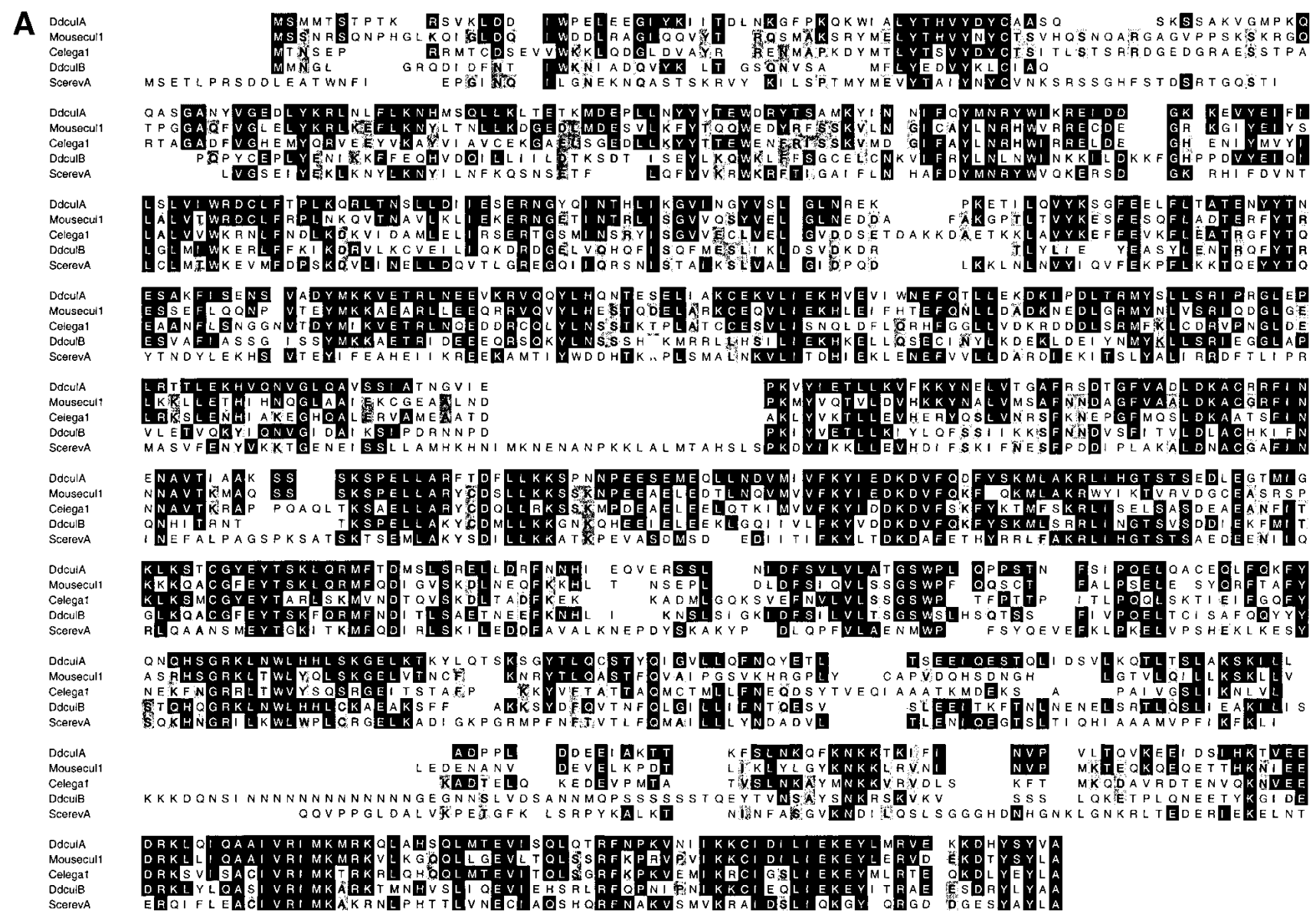

B

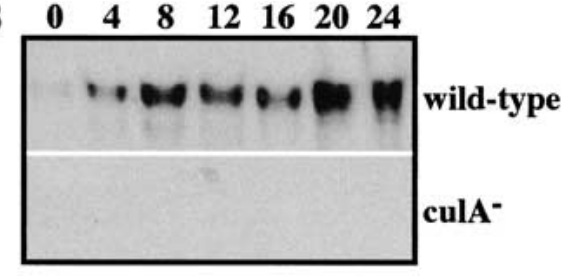

CulA
Figure 1. Derived amino acid sequence of CulA ORF and amino acid sequence comparison of cullins from various organisms and expression pattern of CulA. $(A)$ Dictyostelium cullins, CulA (AF020287) and CulB (AF144717), and Mouse Cullin, M-Cul 1 (AF136441), Saccharomyces cerevisiae culA (U43564), Caenorhabditis elegans cullin 1 (U58083). Identity among the sequences is shown in black and similarity in light gray. Sequences in dark gray indicate the identity among cullins other than CulA. (B) Total RNA from wild-type and culA null cells was isolated from cells at different periods of development as indicated. RNA was size fractionated, transferred to nylon membrane, and hybridized with a CulA probe. highly polarized and chemotax efficiently, culA null cells do not become well-polarized (Fig. 3A). Moreover, although most wild-type cells extend only a single pseudopod in the direction of the cAMP signal, culA null cells have multiple pseudopodia around the periphery of the cell (Fig. 3A, inset). Many of culA null cells exhibit little change in position (they put out multiple pseudopodia but move very little), whereas cells that move do so nondirectionally (their paths appear random), and few cells accumulate around the micropipette tip (Fig. 3A,B).

culA null cells can efficiently induce cAMP-mediated aggregation-stage

but not prestalk- and prespore-specific markers

RNA blot analysis of culA null cells shows that contact sites A $(\operatorname{cs} A)$, a marker for pulse-induced, aggregationstage gene expression, and the post-aggregative marker
LagC, which is induced by high, continuous cAMP through the cAMP receptor during mound formation, are induced with kinetics and levels similar to those of wildtype cells (Fig. 4A; Noegel et al. 1986; Dynes et al. 1994). However, the transcript levels do not decline sharply after $8 \mathrm{~h}$ (Fig. 4A); instead, they decrease slightly and then rise to a high at 20-24 h (see detailed kinetics, Fig. 4B). Expression of the aggregation-stage adenylyl cyclase ACA is maximal between 4 and $8 \mathrm{~h}$ in wild-type cells (Pitt et al. 1992), but in culA null cells, ACA transcripts rise more slowly and continue to accumulate through 20 $\mathrm{h}$ (Fig. 4C). Interestingly, ACA expression is regulated by PKA, whereas other aggregation-stage genes such as $\operatorname{cs} A$ or the cAMP receptor cAR1 are regulated via a distinct signaling pathway ( Mann et al. 1988, 1997; Insall et al. 1994; Schulkes and Schaap 1995). The delayed expression of ACA suggests that culA null cells may exhibit a defect in PKA-mediated events. 


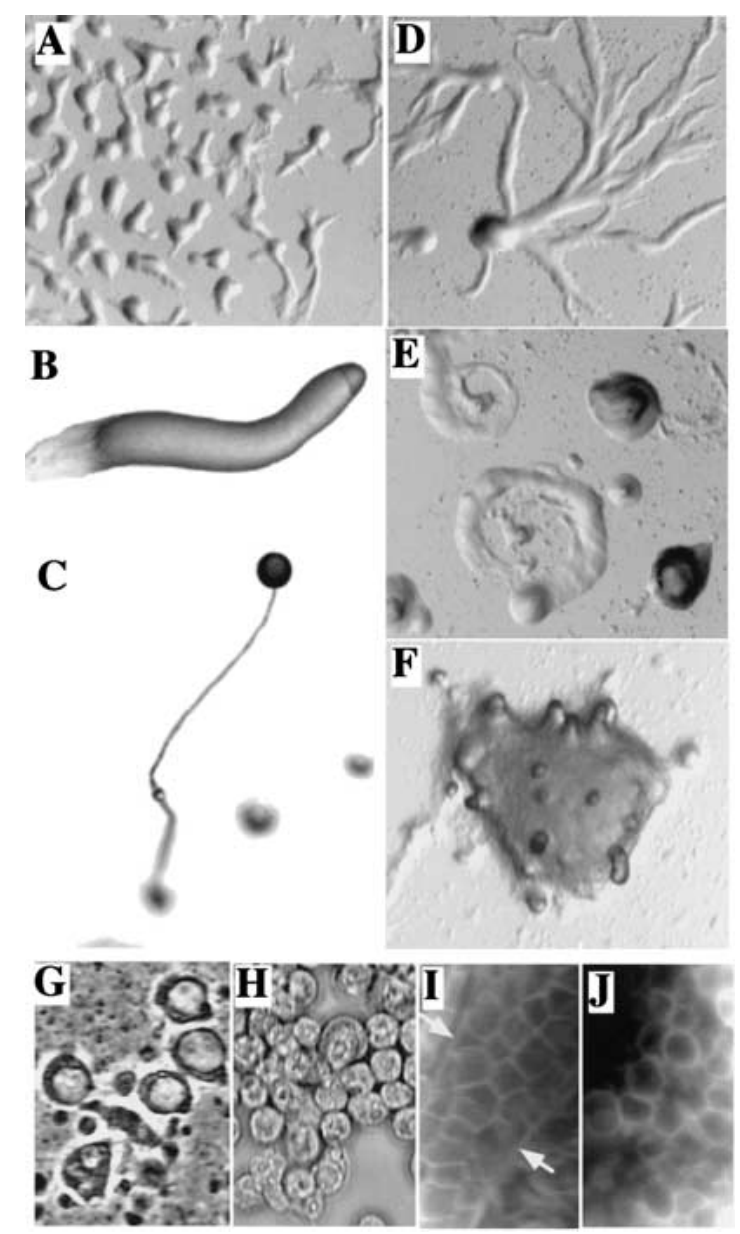

Figure 2. Developmental morphology of Dictyostelium culA null and wild-type strains. Cells were developed on $12 \mathrm{mM}$ $\mathrm{Na} / \mathrm{KPO}_{4}$-containing agar plates $(\mathrm{pH} 6.2)$ and photographed at different stages (see Materials and Methods). $(A-C)$ Wild-type cells at 12,16 , and $24 \mathrm{~h}$ of development. $(D-F)$ culA null cells at 12,16 , and $24 \mathrm{~h}$ of development. Relative magnifications $(A, D)$ $10 \times ;(B, E) 30 \times ;(C, F) 15 \times .(G, H, J)$ Cells from terminally differentiated culA null aggregates at $36 \mathrm{~h}$. Terminally developed structures were collected and placed on glass slides in $10 \mu \mathrm{L}$ of 12 $\mathrm{mM} \mathrm{Na} / \mathrm{KPO}_{4}$ buffer and a coverslip was pressed onto them gently. When these cells were examined under higher magnification (40x objective, phase contrast), at least two types of cells were observed, vacuolated single cells $(G)$ and undifferentiated cells $(H$; most of the cells were undifferentiated). No elliptical spores or spore-like cells were observed. $(I, J)$ Calcofluor staining of a wild-type stalk tube containing stalk cells, $(I)$ stalk tube outer layer is marked with arrows, and (J) stalk-like cells of culA null terminal organisms. Expression of full-length CulA from the constitutive Act 15 promoter rescues the mound-arrest culA null phenotype. These strains produce fruiting bodies in which the sorus (spore-containing portion of the organism) is not fully lifted to the top of the fruiting body. A similar phenotype is observed when CulA is overexpressed in wild-type cells, suggesting the abnormal fruiting body results from overexpression or misexpression of CulA.

We detect no expression of the prestalk-specific gene ecm $A$ or the prespore-specific gene SP60/CotC and a very low level of expression of $\operatorname{ecm} B$ (compared with wild-type cells), a gene preferentially expressed in a subset of prestalk cells (pstAB and pstB cells) when culA null cells are plated for development (Fig. 4A). Moreover, expression could not be induced in suspension assays (data not shown). We examined cell-type-specific gene expression further using cell-type-specific lac $Z$ reporters lecmAO/lac $Z^{-}$expressed in pstA cells and at lower levels in pstO cells; ecmB/lac $Z^{-}$expressed in pstB cells and pstAB cells; $S P 60 / 1 a c Z^{-}$expressed in prespore cells). $c u l A$ null cell aggregates carrying ecmB/lacZ had a small fraction of stained cells, which were scattered throughout the aggregates (data not shown). lacZ expression studies showed no staining by use of prestalk A/O or prespore reporters under standard staining conditions, although we observe very weak staining of scattered cells if the incubation is extended for 10 times the normal period (data not shown).

To examine whether CulA must function in prestalk or prespore cells, we expressed CulA protein in culA null cells from either the ecmAO prestalk-specific or the $S P 60$ prespore-specific promoter. Expression from the ec$m A O$ prestalk-specific promoter results in a mature fruiting body with an enlarged sorus containing mature spores and a shorter, thicker stalk than is observed in a wild-type fruiting body (compare fruiting bodies in Figs. $2 \mathrm{C}$ and $5 \mathrm{~A}$, open arrow; data not shown). When CulA is expressed from the prespore promoter, the mounds form a fruiting-body-like structure on top of an enlarged, elongated basal disk (Fig. 5B, see region marked with the solid arrow; no stalk tube is observed; data not shown). The large, glassy sorus (Fig. 5B, open arrow) contains $<10 \%$ of the spores in wild-type fruiting bodies (data not shown). The results suggest that CulA function is preferentially required in prestalk cells to properly regulate cell-type differentiation and spore maturation via a noncell-autonomous pathway. The partial complementation seen with expression of CulA from a prespore promoter may result from a cell-autonomous requirement of CulA in prespore cells or be due to the ability of Dictyostelium cells within multicellular aggregates to auto-regulate their cell-type proportions by dedifferentiating and redifferentiating into the cell type whose proportion is reduced (Raper 1939). The very low level of expression from the exogenous ecmAO and SP6O promoters observed in the lac $Z$ reporter studies in culA null cells presumably allows a low level of CulA expression, initiating an autoregulatory loop that results in higher CulA expression, cell-type differentiation, and the resulting complementation of the culA null phenotypes.

\section{Suppression of culA and fbxA null phenotypes by overexpression of the PKA catalytic subunit}

PKA is required for multiple developmental decisions in Dictyostelium, including proper chemotaxis, prestalk and prespore cell-type differentiation, and spore maturation (see Introduction for references). The phenotypes of culA null cells are reminiscent of those of other mutant strains that are thought to be defective in the PKA pathway (Shaulsky et al. 1996, 1998; Aubry et al. 1997; Loo- 
A

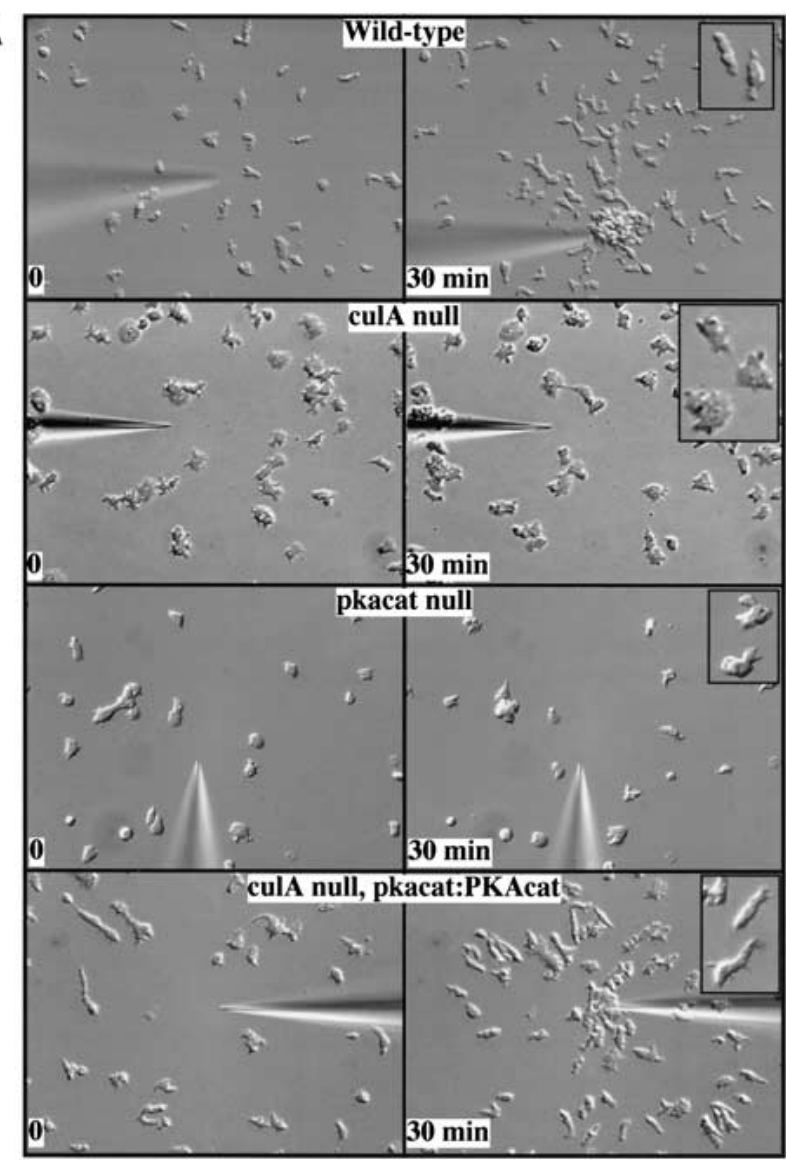

B

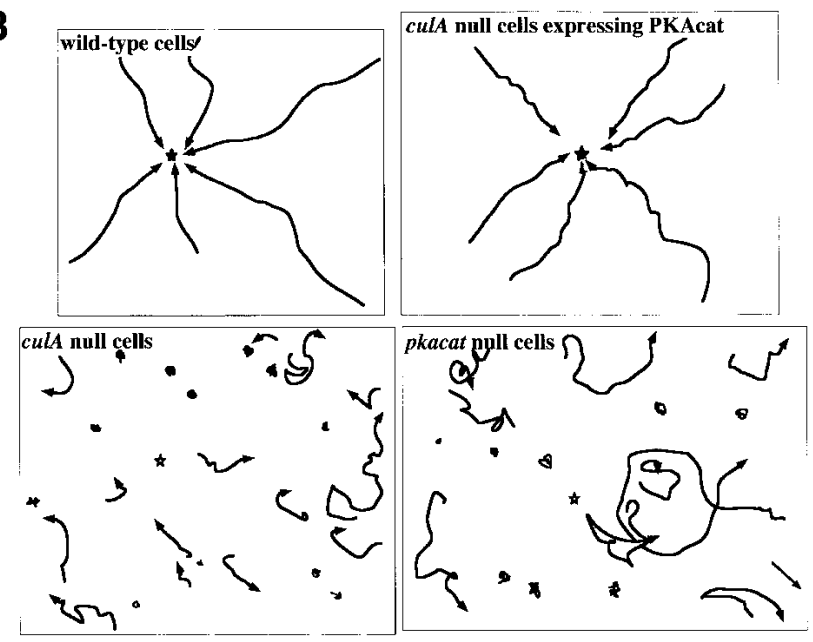

Figure 3. Chemotaxis assay of wild-type and mutant cells. $(A)$ Cells were washed free of medium and pulsed with $30 \mathrm{nM}$ cAMP every $6 \mathrm{~min}$ for $5 \mathrm{~h}$, washed, plated on a glass coverslip embedded in a Petri dish in $\mathrm{Na} / \mathrm{KPO}_{4}$ buffer, and examined as described previously (Meili et al. 1999). The micropipette contains $150 \mu \mathrm{M}$ cAMP. The chemotaxis was recorded for $30 \mathrm{~min}$ with frames taken $6 \mathrm{sec}$ apart. The following strains are shown: wild-type cells, culA null cells, culA null cells overexpressing PKAcat from its own promoter, pkacat null cells. The insets depict magnification of representative cells. $(B)$ Tracings of the chemotactic movement of individual cells from the time-lapse videos depicted in $A$. (Asterisk) The position of the tip of the micropipette. When culA null cells are pulsed for 7 rather than $5 \mathrm{~h}$, we observe the same chemotaxis defect. mis et al. 1997; Wang and Kuspa 1998). To examine whether the culA mutant phenotype might result from reduced PKA activity, we tested whether overexpressing the PKA catalytic (PKAcat) subunit suppresses the phenotype. Under these conditions, PKA activity is constitutive. Overexpression of PKAcat from its own promoter in culA null cells suppresses the culA null prestalk and prespore gene expression and morphogenesis defects (Figs. 4A and 5C). The culA chemotaxis phenotypes could be similarly suppressed (Fig. 3A,B). These results suggest that PKAcat can bypass the requirement of CulA function for development, suggesting that the culA phenotypes result from reduced PKA activity. If the culA null cell chemotaxis defect is due to decreased PKA activity, the chemotaxis phenotype of pkacat null cells might be similar to that of culA null cells. Figure 3, A and $\mathrm{B}$ show that this is the case; some of the pkacat null cells show little cell movement, those that move do so randomly with respect to the cAMP gradient, and the cells are not polarized in cAMP gradients. Our results cannot distinguish between PKA functioning at the time of chemoattractant stimulation or acting transcriptionally to control the expression of genes required for chemotaxis.

Our results suggest that CulA is preferentially required during the multicellular stages in prestalk cells for both prestalk and prespore cell differentiation and formation of mature spore cells. Previous results show that $f b x A$ is preferentially expressed in prestalk cells and is required in these cells for proper cell-type proportioning. $f b x A$ null cells have a propensity to differentiate into prespore cells and exhibit a reduction in prestalk gene expression and a reduced number of prestalk cells (Fig. 4A ; Ennis et al. 2000; Nelson et al. 2000). Unlike culA null cells, the $f b x A$ null cell phenotypes suggest that FbxA is required predominantly during the multicellular stages, as $f b x A$ null cells do not exhibit aggregation-stage chemotaxis or gene expression defects. [Note: the $f b x A$ null phenotypes vary in severity depending on the genetic background and are most severe in strain $\mathrm{KAx}-3$, the parental strain used in this study (data not shown; Nelson et al. 2000)]. In this strain, most $f b x A$ null aggregates arrest at the mound stage (data not shown; Nelson et al. 2000), ecmA prestalk and SP60/ $\cot C$ gene expression is delayed, and the level of ecm $A$ expression is reduced compared with that in wild-type cells (Fig. 4), consistent with previous findings (Nelson et al. 2000).

The knowledge that F-box/WD40-repeat-containing proteins and cullins are involved in ubiquitin-mediated protein degradation and $c u l A$ and $f b x A$ null cells share some similarities in their phenotypes suggested that CulA and FbxA may function on the same genetic pathway. If this were true, PKAcat overexpression should suppress the $f b x A$ null phenotype. In fact, expression of FbxA or PKAcat restores the ability of the cells to form fruiting bodies containing mature spores (data not shown) and ecmA expression to wild-type levels (Fig. 4A). These observations are consistent with PKAcat functioning downstream from both CulA and FbxA in a 
Mohanty et al.

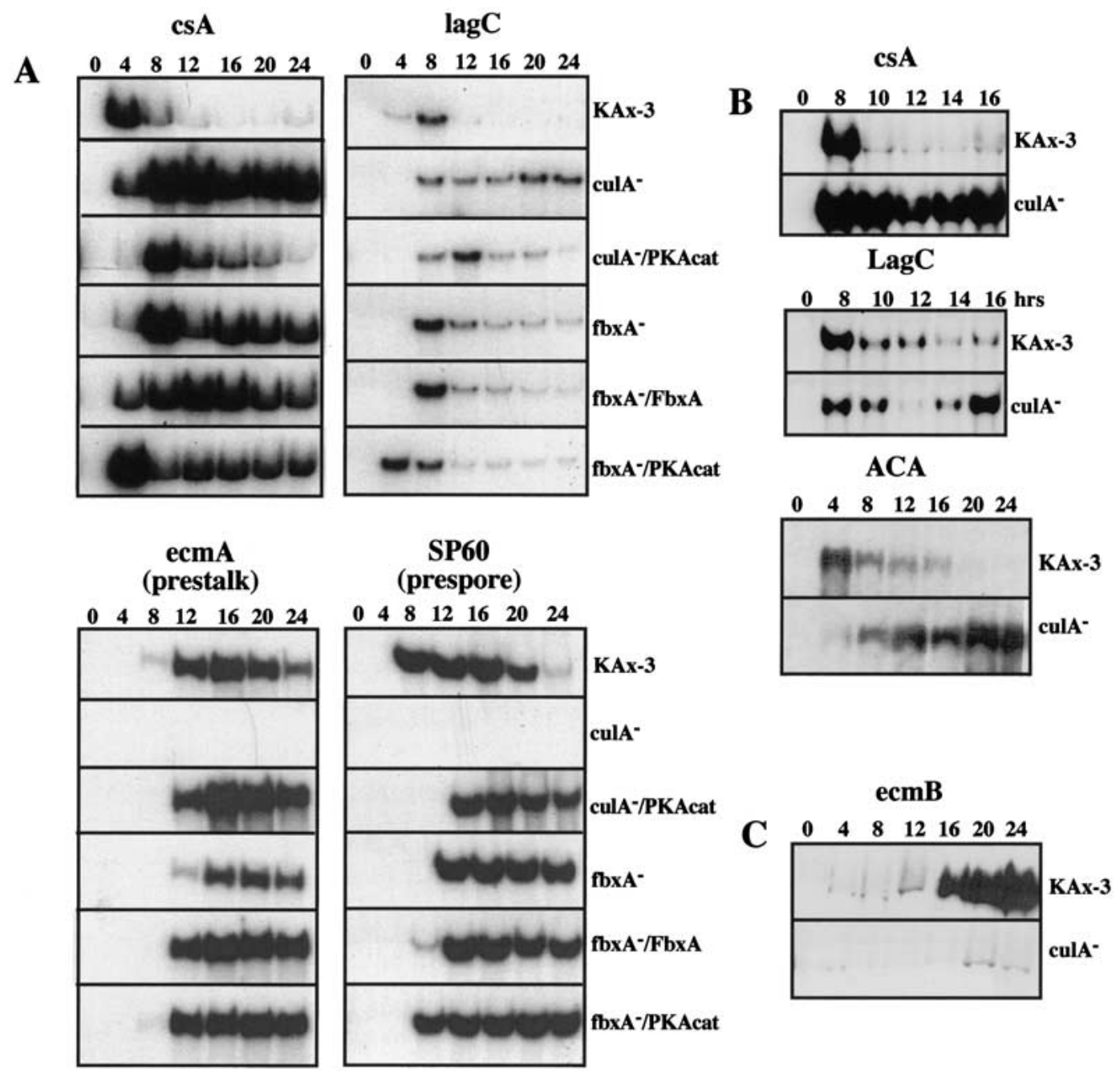

Figure 4. RNA blot analysis of gene expression. Total RNA from wild-type and mutant strains was isolated from cells at different periods of development as indicated. RNA was size fractionated, transferred to nylon membrane, and probed for gene expression as indicated.

regulatory pathway that controls chemotaxis, cell-type differentiation, and morphogenesis. Differences in the severity of the phenotypes between $c u l A$ and $f b x A$ null cells suggest that the two proteins may regulate some distinct as well as overlapping downstream proteins (see Discussion).

\section{CulA and FbxA control the degradation of the cAMP-specific phosphodiesterase RegA}

Three Dictyostelium proteins that directly regulate PKA function are the intracellular, cAMP-specific phosphodiesterase RegA (Shaulsky et al. 1996, 1998; Thomason et al. 1998, 1999b) and the PKA catalytic (PKAcat) and regulatory (PKA-R) subunits. Preferential degradation of RegA or PKA-R could result in increased PKA activity, whereas a decrease in the rate of their degradation could lead to decreased PKA function. In the case of RegA, a reduced rate of degradation (elevated RegA levels and thus PDE activity) would result in reduced cAMP levels and PKA activity. Degradation of PKA-R would cause a release of free PKAcat, leading to increased kinase activity.

Figure 6A shows that in wild-type cells, RegA protein levels, detected by use of a RegA-specific antibody (Thomason et al. 1998), increase from a low to a maximum in vegetative cells at 4 and $8 \mathrm{~h}$, the time of mound formation, whereupon the levels rapidly decrease and then remain low. In culA null and $f b x A$ null cells, RegA protein is at a moderate level in vegetatively growing cells, increases upon starvation, but remains high, at a level that is greater than that in wild-type cells at $8 \mathrm{~h}$ of development (Fig. 6A; Thomason et al. 1998). As observed previously, two RegA bands are visible (Thomason et al. 1998) that are absent in blots of regA null cells. The lower band is stronger in our samples than that observed previously (Thomason et al. 1998). This could be due to increased proteolysis in our samples or to differences in the parental cell line, with the lower band not being an artifact of sample preparation. Overexpression of CulA 


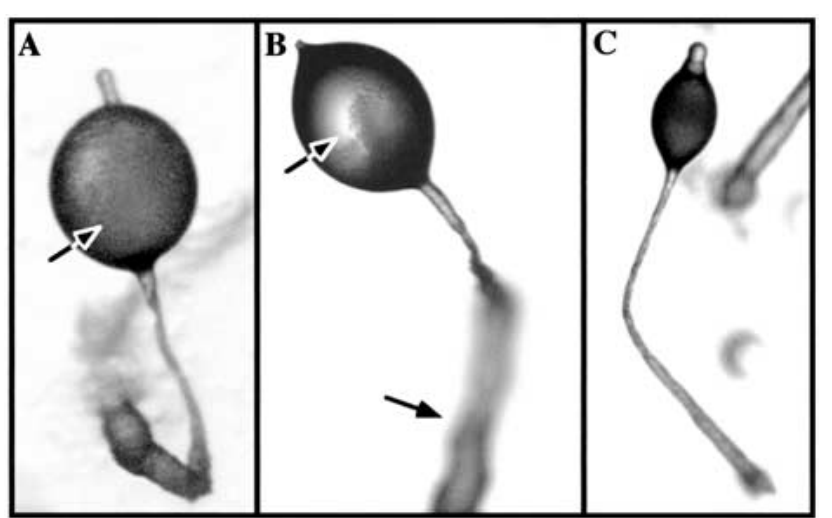

Figure 5. Complementation of culA null cells. (A) Overexpression of CulA from the prestalk promoter ecmA in culA null cells. The complementation is partial. The terminal structures have large sori on short stalks. The open arrowhead shows a sorus full of mature spores. $(B)$ Overexpression of CulA from the prespore promoter SP60 in culA null cells results in a partial rescue of the culA null phenotype. The fruiting bodies have large, empty sori with few spores. The glassy appearance of a sorus is indicated with an open arrow. The solid black arrow indicates the enlarged stalk/basal disc. $(C)$ Overexpression of PKAcat from its own promoter in culA null cells gives rise to normally proportioned fruiting bodies.

in culA null cells or FbxA in $f b x A$ null cells restores the reduction in RegA levels at $12 \mathrm{~h}$ of development, but not the low level in vegetative cells (Fig. 6A). As Dictyostelium CulA is most closely related to mouse Cul-1, we tested whether Cul-1 could complement the culA null phenotype. Expression of Cul-1 in culA null cells restores the regulated degradation of RegA, although the timing is delayed (Fig. 6A). These strains undergo morphogenesis, but produce abnormal-looking fruiting bodies (data not shown).

To examine whether the persistence of high levels of RegA protein in culA null or $f b x A$ null cells is due to the developmental arrest of these strains, we examined RegA protein levels in culA null and $f b x A$ null cells overexpressing PKAcat $\left(c u l A^{-} / \mathrm{PKAcat}\right.$ or $\mathrm{fbx} A^{-} / \mathrm{PKA}$ cat). As shown in Figure 6A, RegA levels persist in these strains in later development as in the parent strain, although these strains develop normally. These findings indicate that PKAcat does not suppress the culA or $f b x A$ null cell phenotypes by restoring the degradation of RegA protein, and that the elevated levels of RegA in culA and $f b x A$ null strains are not due to the developmental arrest of these strains.

The MAP kinase ERK2 is required for cAMP-stimulated cAMP accumulation (Segall et al. 1995) and is thought to antagonize the action of RegA (A. Kuspa, pers. comm.). erk2 null cells exhibit a phenotype that is more severe than that of either culA or $f b x A$ null cells; the cells are aggregation deficient (Segall et al. 1995). Moreover, overexpression of PKAcat in erk2 null cells suppresses the erk2 null phenotypes and these cells develop normal fruiting bodies (Aubry et al. 1997), paralleling our results with $c u l A$ and $f b x A$ null cells. As interaction of substrates with specific F-box-containing proteins and an SCF complex is often mediated by phosphorylation (Chen et al. 1996; Willems et al. 1996, 1999; Karin and Delhase 2000), we tested whether erk2 null cells also exhibit elevated levels of RegA. Figure 6A shows that this is the case. In addition, as in $c u l A^{-} /$PKAcat or $f b x A^{-} /$ PKAcat cells, the elevated RegA levels persist in erk2-/ PAKcat cells, even though erk2-/PAKcat cells develop normally. Thus, the continued high level of RegA in erk2 null cells is not due to the inability of erk2 null cells to proceed through development.

We also examined the levels of PKAcat and PKA-R in some of these strains. The level of PKAcat protein is very low in vegetative cells, increases by $8 \mathrm{~h}$, and remains high throughout development (Fig. 6C). In culA null cells, the level of PKAcat protein is high in vegetative cells and remains high, whereas PKA-R exhibits a slightly reduced level compared with wild-type cells throughout the time course. Levels in vegetative cells are slightly below those at other stages. erk2 null cells exhibit high vegetative levels of PKAcat.

\section{CulA and FbxA form a complex with $\operatorname{Reg} A$ that is dependent on ERK2 function}

One pathway for ubiquitin-mediated protein degradation involves an SCF complex containing a Skp1 family member, a cullin, an F-box/WD40-repeat-containing protein, and the enzymes involved in ubiquitin transfer (see Introduction). In this complex, the WD40 repeats of the F-box-containing protein bind the substrate, often in a phosphorylation-dependent manner (Chen et al. 1996; Willems et al. 1996, 1999; Deshaies 1999; Maniatis 1999; Karin and Ben-Neriah 2000). If CulA and FbxA are involved in RegA degradation, then we might expect all three proteins to be present in a complex. As the F-box/ WD40-repeat-containing protein binds the protein targeted for ubiquitination, we expressed a GST fusion protein containing the carboxy-terminal F-box/WD40 repeats of FbxA in wild-type cells and $c u l A, f b x A, \operatorname{reg} A$, and erk2 null cells. The cells were plated for development. Samples were taken at various times and the GST fusion protein was isolated from cell lysates by use of glutathione-Sepharose and analyzed by Western blots for the presence of GST-FbxA:F-box/WD40 fusion protein, RegA, and cullin by use of anti-GST, anti-RegA, and anti-human cullin 1 (Cul-1) antibodies, respectively (Fig. $6 \mathrm{~B})$. Blots with the anti-GST antibody revealed a similar level of expression of the fusion protein at most time points. Controls in which GST alone (not a fusion protein) was expressed in all of the strains were performed to ensure that any complex formation was dependent on the FbxA:F-box/WD40 domain of the fusion protein (Fig. 6D).

Figure 6B indicates that RegA is associated with GSTFbxA:F-box/WD40 starting at $4 \mathrm{~h}$ of development in wild-type cells, the onset of aggregation and the time point at which we first observe RegA protein in wholecell extracts. The amount of RegA in the complex is the highest after $8 \mathrm{~h}$, even though total cell RegA levels decrease as development proceeds. A complex containing 

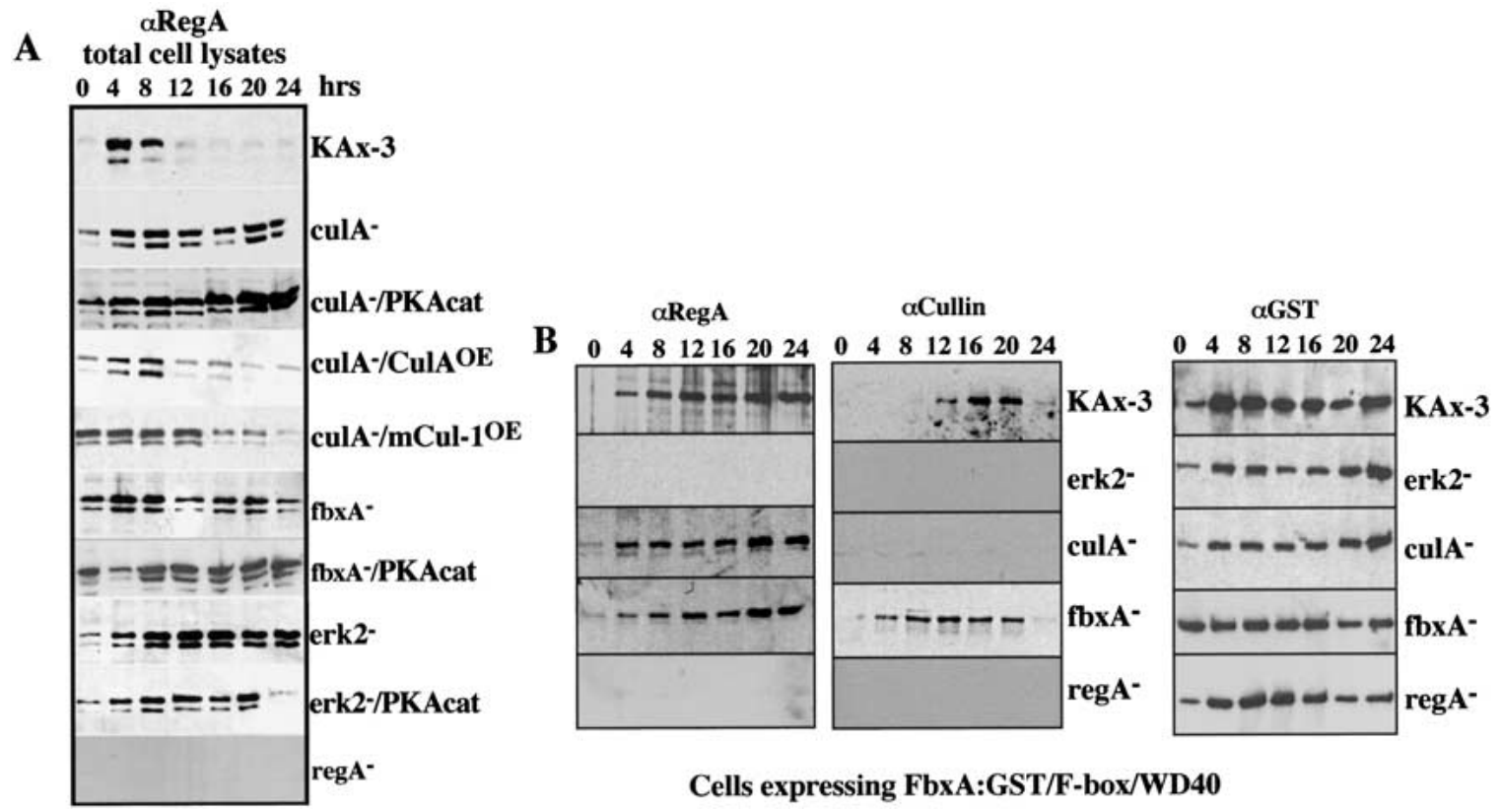

Cells expressing FbxA:GST/F-box/WD40
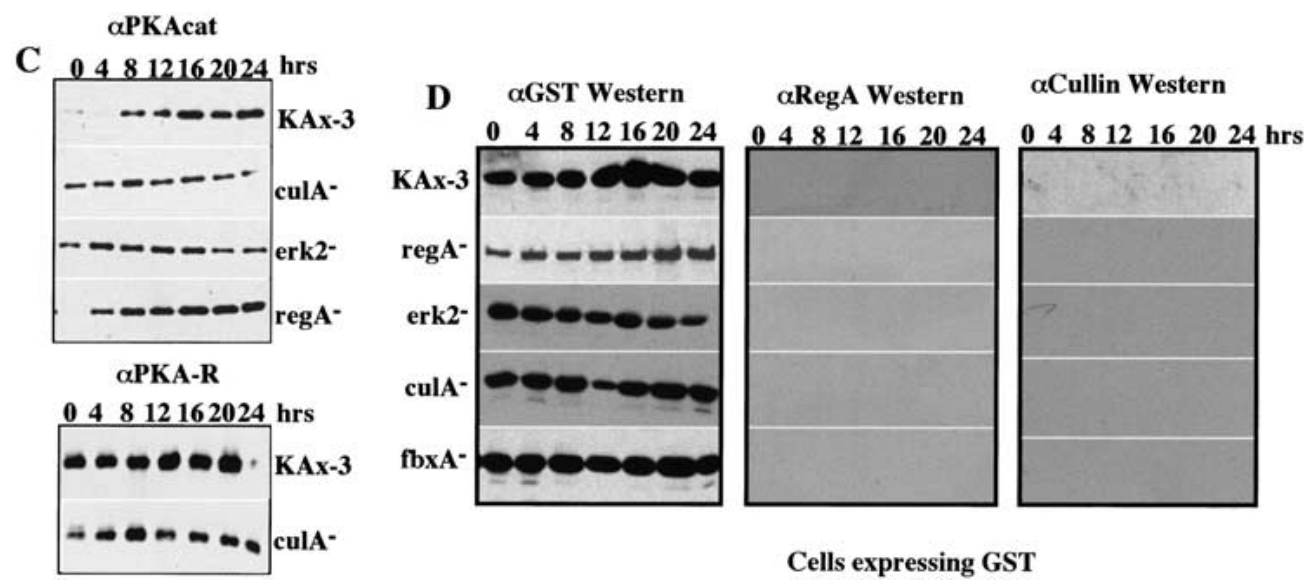

Figure 6. Western blots of RegA, PKAcat, and PKA-R in various cell lines. (A) Cells were harvested at various developmental stages, washed, solubilized in lysis buffer ( $20 \mathrm{mM}$ Tris at $\mathrm{pH} 7.2,1 \%$ SDS, $1 \mathrm{mM}$ EDTA, $1 \mathrm{mM} \mathrm{PMSF})$, and immediately boiled at $100^{\circ} \mathrm{C}$ for $3 \mathrm{~min}$. Proteins were sized by SDS-PAGE using $8 \%$ gels. The gels were transferred to PVDF membrane and the blots were probed with the anti-RegA antibody $(\alpha$ RegA) (Thomason et al. 1998). (B) Wild-type and mutant strains expressing GST-FbxA:F-box/WD40 were lysed and the 10,000 $\times$ G supernatant was adsorbed to g-Sepharose. The beads were washed and the bound material was examined by Western blot analysis and probed with anti-RegA, Cul-1, and GST antibodies (see Materials and Methods). (C) Samples were taken and processed as described for $A$ and probed with either anti-PKAcat, or anti-PKA-R antibodies, as indicated. The anti-PKAcat and anti-PKA-R antibodies were a generous gift of M. Veron (Institut Pasteur, Paris). (D) The experiment is the same as described in $B$ except that it was performed using cells that were transformed with GST alone.

RegA was also observed in culA null and $f b x A$ null cells, the latter result indicating that endogenous FbxA, and thus the amino terminus of $\mathrm{FbxA}$, is not required for this complex. In these strains, complexes can be observed in vegetative cells. The absence of detectable RegA protein in wild-type vegetative cells may be due to rapid turnover that is altered in the mutant strains. As expected, no RegA is observed in regA null cells (Thomason et al. 1998). Interestingly, no RegA is associated with the complex in erk2 null cells, suggesting ERK2 function is required for complex formation as well as RegA degradation.
The anti-cullin antibody reveals a cullin associated with GST-FbxA:F-box/WD40 in wild-type cells starting at low levels at $8 \mathrm{~h}$, when we detect a weak signal, and increasing at subsequent times in development up to 20 h. In $f b x A$ null cells, a weak cullin band is observed in vegetative cells and a strong band is seen at $4 \mathrm{~h}$, which is consistent with the expression pattern of CulA transcripts regA null cells. The absence of a cullin band in $\operatorname{reg} A$ null cells suggests that GST-FbxA:F-box/WD40 may need to form a complex with a target protein to recruit a cullin. The absence of a cullin band in erk2 null cells is consistent with this model, as no RegA is present 
in the complex. In contrast, our results with culA null cells show that CulA is not needed to form a complex containing GST-FbxA:F-box/WD40 and RegA, although we cannot discount the possibility that another cullin is present that does not cross-react with our antibody. However, as we observe no signal with this antibody in culA null cells, we suggest that the cullin in the complex is CulA. No complex is observed with GST alone in any strain tested (Fig. 6D). We propose that RegA complexes with the F-box/WD40 repeat domain of FbxA via an ERK2-dependent pathway leading to RegA's degradation.

The onset of RegA degradation at the time of mound formation suggests that RegA degradation could be regulated by increases in extracellular cAMP known to be required for induction of post-aggregative gene expression (see Aubry and Firtel 1999). To examine this hypothesis, we took advantage of the ability to make cells competent to induce cell-type-specific gene expression by high, continuous cAMP that functions through the serpentine, cell-surface cAMP receptor by mimicking early development in suspension (Insall et al. 1994; Schnitzler et al. 1995). Addition of high, continuous cAMP then induces cell-type-specific gene expression. As shown in Figure 7, high cAMP induces the decrease in RegA protein levels in competent wild-type but not culA null cells. Cells that do not receive high levels of cAMP show some reduction in RegA levels during later time points that coincide with some aggregate formation, which can induce cell-type-specific gene expression through the endogenous production of cAMP. This is not seen in culA null cells. The results are consistent with a model in which mound formation leads to a reduction in RegA protein levels that is dependent on CulA function.

\section{Discussion}

CulA encodes a cullin required for aggregation, morphogenesis, and cell-fate pathways

Cullins are a component of the SCF complex involved in protein ubiquitination. culA null cells are defective in a

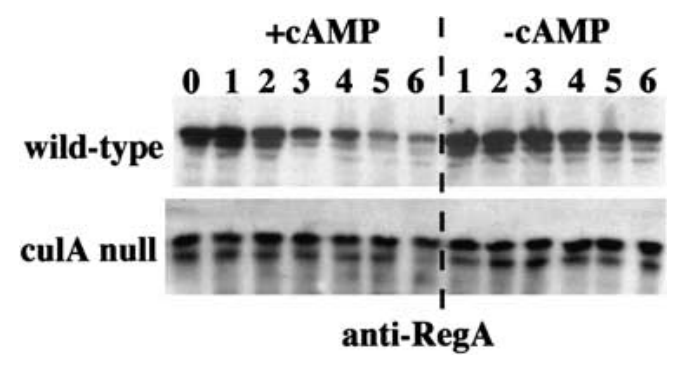

Figure 7. Induction of loss of RegA in suspension culture. Cells were pulsed with $30 \mathrm{nM}$ cAMP for $5 \mathrm{~h}$. The culture was split with one-half +CAMP, receiving cAMP to a final concentration of 300, and the other half not receiving cAMP (-cAMP). Time points were taken every $45 \mathrm{~min}$ and RegA protein levels in whole cell lysates determined as in Fig. 6A. (0) The time point after $5 \mathrm{~h}$ of pulsing with $30 \mathrm{nM}$ cAMP. Other time points were taken at 45-min intervals. Cell-type-specific gene expression is seen after $1.5 \mathrm{~h}$ of stimulation (Mehdy and Firtel 1985). variety of cellular and developmental processes, including chemotaxis during aggregation, morphogenesis, and cell-type differentiation. All of these defects can be suppressed by the expression of PKAcat from its own promoter, suggesting that the underlying defect that results in the observable culA null phenotypes is an inability to properly activate PKA at distinct stages of development. Consistent with this finding, pkacat null cells exhibit similar chemotaxis defects. We note that $\operatorname{reg} A$ null and culA null cells, which we view as RegA hypermorphs, both exhibit chemotaxis defects, suggesting that PKA activity must be accurately regulated for this pathway (this work; Wessels et al. 2000). Whereas Dictyostelium CulA is most closely related to mammalian Cul-1, which regulates cyclin E degradation (Dealy et al. 1999; Wang et al. 1999b), we see no evidence of a cell-cycle phenotype in culA null cells. However, cells of higher eukaryotes continue to cycle in the absence of Cul-1 (Kiproes et al. 1996).

A major developmental defect of culA null cells is their inability to initiate the induction of the pathway leading to pstA/O and prespore differentiation. In addition, the expression levels of the aggregation and postaggregation genes do not decrease upon mound formation, probably due to the inability of these strains to undergo morphogenesis, a defect observed in spalten null cells (Aubry and Firtel 1998). As no ecmA gene expression is seen in culA null cells, we expect that the vacuolated cells observed in culA null mounds are basal disk cells and not stalk cells (Jermyn et al. 1989, 1996).

Studies on the RING-domain-containing protein rZIP and the protein phosphatase 2C Spalten suggested that prespore differentiation is regulated, in part, through a nonautonomous pathway mediated by prestalk cells (Balint-Kurti et al. 1997; Aubry and Firtel 1998, 1999). We suggest that CulA and FbxA function predominantly in prestalk cells to control multicellular development; good complementation of the culA null phenotype is achieved when CulA is expressed from a prestalk but not a prespore promoter. Consistent with this finding, $f b x A$ null slugs have reduced numbers of prestalk cells and FbxA expression is greatly enriched in prestalk cells (Nelson et al. 2000). Results using chimeras suggest that the inability of culA null cells to induce pstA/O and prespore gene expression is also partially nonautonomous, as ecmAO/lacZ and SP60/lacZ cell-type-specific reporters are weakly expressed in culA null cells in chimeras but not at all when culA null cells are developed alone (data not shown). This weak ecmAO/lacZ expression is presumably not due to the fact that the chimeras develop further than culA null cells, as we observe ec$m A O / l a c Z$ expression in early mounds of chimeras. However, culA null cells must also have cell-autonomous defects; for example, the defects in morphogenesis at the mound stage probably result from the combined defects in chemotaxis and prestalk cell differentiation as the tip is formed from the differential, chemotaxis-mediated sorting of the prestalk cells (Abe et al. 1994; Rietdorf et al. 1996; Clow et al. 2000). 
CulA and FbxA may regulate the PKA pathway via differential protein degradation

We propose that the defect in $\operatorname{cul} A$ and $f b x A$ null strains is due, in part, to an inability to degrade the cAMP-specific phosphodiesterase RegA, which leads to reduced levels of cAMP and decreased PKA activity. We show that PKAcat overexpressed from its own promoter rescues the culA and $f b x A$ null cell phenotypes. Whereas RegA levels decrease as the mound forms in wild-type cells, our findings indicate that they remain high in culA, fbxA, and erk2 null cells. This is not due to developmental arrest, as the levels remain high in these strains when they are transformed with PKAcat, which suppresses the developmental defects. Normal expression of $S P 60 / \cot C$ and ecmAO requires PKA activity (Mann and Firtel 1991; Hopper et al. 1993a,b; Zhukovskaya et al. 1996; Mann et al. 1997; Loomis 1998). The inability to induce the expression of these genes in developing culA null cells or in response to exogenous cAMP in cell suspension is consistent with a defect in PKA activation in these cells.

We find that RegA and a cullin are present in a complex in vivo with the F-box/WD40 repeats of FbxA expressed as a GST fusion, as might be expected if CulA and FbxA are involved in RegA degradation. According to our understanding of SCF and other complexes that mediate ubiquitination of proteins targeted for degradation, the F-box/WD40 repeat-containing protein would bind the substrate, in this case RegA. The fact that binding is achieved with the F-box/WD40 repeats of FbxA and not the whole FbxA protein suggests that the F-box/ WD40 repeat domain is sufficient for complex formation. However, expression of the FbxA GST-F-box/ WD40 repeats in $f b x A$ null cells shows only a very weak suppression of the $f b x A$ null phenotype (the cells proceed only slightly further in development; S. Mohanty and R.A. Firtel, unpubl.), suggesting that the long FbxA amino-terminal region is important in FbxA's genetic role to regulate cell-fate decisions. As discussed in the Results section, we interpret our anti-Cul-1 Western blot results to mean that most probably CulA, rather than another Dictyostelium cullin, participates in a complex with FbxA, at least during the multicellular stages of development.

We had tested the effects of the proteasome inhibitors MG132 (tested at 50 and $250 \mu \mathrm{M}$ ), MG262 (tested at 1 and $5 \mu \mathrm{M}$ ), and clasto-lactocystin beta-lactone (tested at 1 and $5 \mu \mathrm{M})$ as a different approach to examine whether RegA degradation is mediated by the proteasome pathway (S. Mohanty and R.A. Firtel, unpubl.). Unfortunately, none of these inhibitors caused any observable developmental delay/arrest when added as much as $2 \mathrm{~h}$ before mound formation. Our studies on CulA and previous studies on the role of UbcB /Clark et al. 1997; Chung et al. 1998) indicate that ubiquitin-mediated degradation is essential for progression past the mound stage. Therefore, we expect that the proteasome inhibitors we tested did not block proteasome function in vivo, possibly because of permeability into the cells.
We also found that erk2 null cells have elevated levels of RegA protein and that these levels do not decrease upon overexpression of PKAcat, even though the cells develop. Moreover, the presence of RegA in a complex with FbxA:GST-F-box/WD40 requires ERK2 function. Some proteins are targeted for SCF complex formation via phosphorylation, which allows the binding of the protein to the WD40 repeat domain /Chen et al. 1996; Willems et al. 1996, 1999; Deshaies 1999; Karin and Delhase 2000; Tyers and Jorgensen 2000; Verma and Deshaies 2000). Figure 8 depicts a model for the regulatory pathway controlling RegA degradation. We propose that RegA is degraded through the ubiquitin-proteasome pathway via an ERK2-dependant SCF complex containing CulA and FbxA. For simplicity, we suggest RegA is phosphorylated by ERK2 and this phosphorylation is required for complex formation. Alternatively, ERK2 may phosphorylate another protein this is tightly bound to RegA to target both proteins, or regulate another kinase that directly phosphorylates RegA or another protein. Previous studies revealed that ERK2 is activated through the cell-surface cAMP serpentine receptors by cAMP but via a G-protein-independent pathway (Maeda et al. 1996). It is thus possible that part of the receptor-dependent, G protein-independent pathway by which extracellular cAMP mediates cell-type-specific gene expression functions by controlling ERK2 activity and RegA degradation. We also show that in suspension culture, high, continuous cAMP, the signal to induce post-aggregative and cell-type-specific gene expression, induces the loss of RegA protein levels. In support of this model, experiments with an ERK2 temperature-sensitive mutation indicate that ERK2 is required for cell-type-specific gene expression and morphogenesis (Gaskins et al. 1996). There must be other inputs into the regulation of RegA, as RegA is a response regulator and its PDE activity is positively regulated via a two-component His kinase phosphorelay pathway (Shaulsky et al. 1998; Thomason et al. 1998,1999b). Other data suggest that ERK2 is involved in negatively regulating RegA's PDE activity during aggregation (A. Kuspa, pers. comm.).

Whereas our data support the model in Figure 8 depicting RegA regulation by ERK2, CulA, and FbxA, we note that the severities of the phenotypes of erk2, culA, and $f b x A$ null cells are different. erk2 null cells do not aggregate because ERK2's activity is required for the accumulation of CAMP, which functions intracellularly to regulate PKA and is released to act in signal relay as a ligand for the cAMP receptor (Segall et al. 1995). A role of ERK2 in inhibiting RegA activity during aggregation in response to oscillatory signaling (A. Kuspa, pers. comm.) and a second role promoting RegA degradation during multicellular development are consistent with the different functions of cAMP and the kinetics of the responses at these distinct stages of development. culA null cells have a more severe phenotype than that of $f b x A$ cells, which we expect is due to CulA controlling the degradation of a larger set of proteins than FbxA and/ or due to CulA participating with other F-box-containing proteins at different stages of development to control 


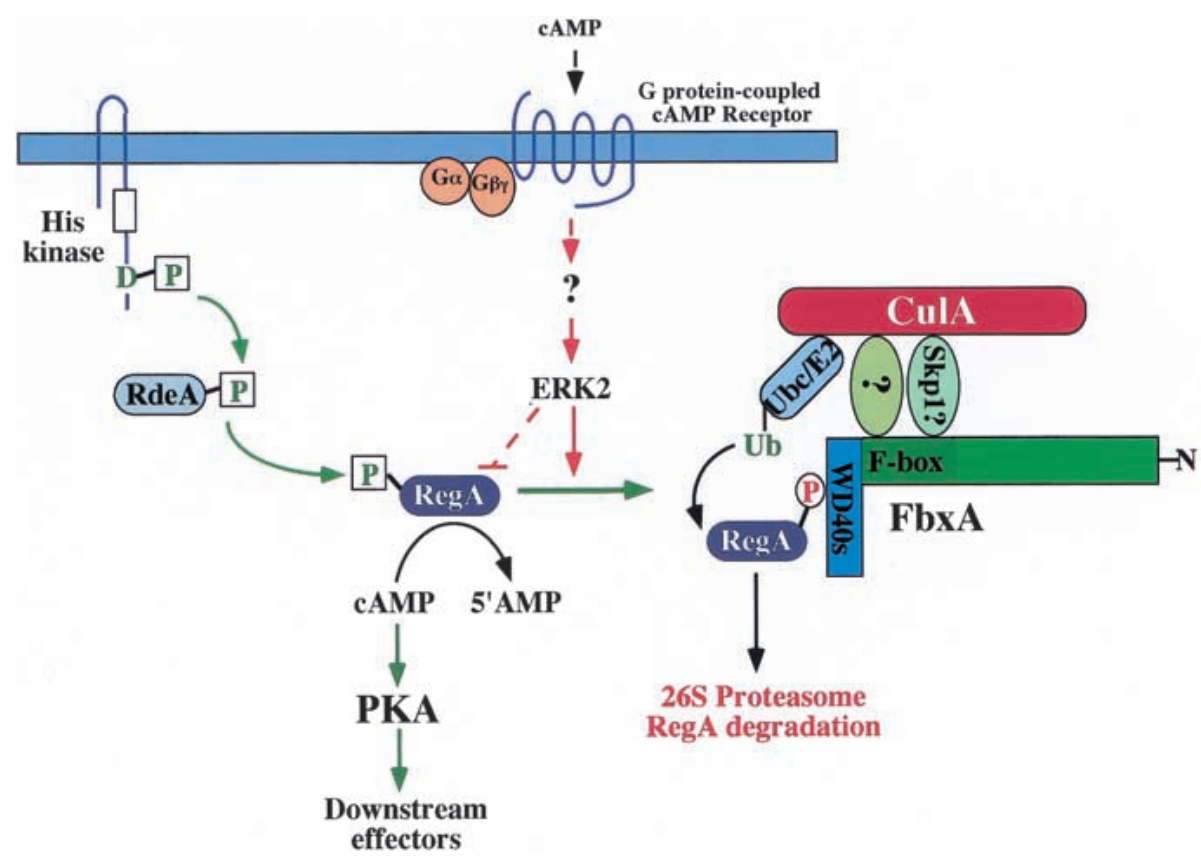

Figure 8. Model of RegA regulation by differential degradation. RegA is a key regulator as it controls, in part, the concentration of intracellular cAMP. RegA is differentially degraded via a pathway that requires the F-box/WD40-repeat-containing protein FbxA and the cullin CulA. The pathway requires ERK2, a MAP kinase activated through the cAMP receptor. We propose that ERK2-mediated phosphorylation of RegA (circled P) targets RegA's interaction with FbxA and the ubiquitination machinery that includes CulA. In addition, RegA's PDE activity is positively regulated by a His kinase two-component phosphorelay pathway (boxed P) (Thomason et al. 1998, 1999b). The His kinase (generic) is shown as a transmembrane protein with a His kinase domain and a response regulator-motif Asp residue, as is the case with known Dictyostelium His kinases (Loomis et al. 1998; Wang et al. 1999a). It transfers the phosphate (boxed P) to a His residue on RdeA, which transfers it to a receiving Asp in the response regulatory domain of RegA, stimulating its activity (Thomason et al. 1998, 1999b). Whereas the His kinase is not specified, the one with a knockout phenotype consistent with this model is (Singleton et al. 1998). RegA PDE activity may be negatively regulated by two-component system pathways during culmination (Thomason et al. 1999a,b). ERK2 may also negatively regulate RegA PDE enzymatic activity during the aggregation stage of development through its direct phosphorylation (A. Kuspa, pers. comm.). This is indicated in the model by the broken line with a bar at the end. It is not known whether ERK2 phosphorylates RegA at different sites or the same sites for these two different modes of regulation.

RegA. As the phenotypes of $e r k 2, f b x A$, and culA null cells can be suppressed PKAcat, we expect that any other developmentally essential proteins that are regulated by CulA may also function in the PKA pathway and/or can be bypassed by high, constitutive PKA activity. We expect that CulA and probably FbxA function in other pathways and are not dedicated solely to the degradation of RegA.

In conclusion, our analysis further elucidates regulatory pathways by which targeted protein degradation is required to mediate cellular transitions. As with the degradation of proteins in the cell cycle, degradation of RegA is required for cells to move from one cellular state or developmental stage to another. We define a regulatory network by which a designated cullin and an F-boxcontaining protein control PKA activity through the degradation of a cAMP-specific phosphodiesterase. Our results are consistent with this pathway being regulated through a MAP kinase pathway.

\section{Materials and methods}

\section{Cell and molecular biology}

Methods for REMI mutagenesis, cell culture, RNA and DNA extraction, Northern and Southern blot hybridization, cell transformation, and $\beta$-gal histochemical analysis have been described previously (Kuspa and Loomis 1992; Clark et al. 1997). Time-lapse video microscopy was performed as described previously (Ma et al. 1997).

A CulA gene knockout was created by inserting a BglII linker into full-length CulA cDNA at the HincII site. The Bsr resistance expression cassette was inserted in the BgIII site. This construct was digested with EcoR 1 and $A p a \mathrm{I}$ and electroporated in KAx-3 wild-type cells (Sutoh 1993; Lee et al. 1997).

We used the pGEX vector as template to PCR amplify the GST. The primers used were GST2TF1 (GTATATACTAG TAAAAAAATGTCCCCTATACTAGGTTATTGG) and GST 2TR1 (GTTTTTGAATTCCATATGGGTACCACCACCAAA CGTGGCTTGCC). We introduced a glycine-glycine linker to minimize potential steric hindrance in multiprotein interactions or complex formation. The PCR product of GST2TF1 and GST2TR1 was digested with SpeI and EcoRI and ligated with the EcoRI-XhoI fragment consisting of F-box and WD40 repeats of the FbxA protein and the DEP vector digested with SpeI and XhoI (a triple ligation). This construct was inserted into the Dictyostelium DEP expression vector Exp4(+).

The full-length mCul-1 cDNA (Dealy et al. 1999) was cloned into the same Dictyostelium expression vector.

\section{Immunoprecipitation}

GST and FbxA-GST constructs were transformed into Dictyo- 
stelium cells by use of standard techniques (Mann et al. 1998). We grew cells in HL-5 medium supplemented with $20 \mu \mathrm{g} / \mathrm{mL}$ G418. Four clones were selected for each overexpression and the strains were maintained by growth in G418. The expression levels of GST were comparable in wild-type cells and various null clones.

For Western blot analysis, cells were harvested at various developmental stages, washed, solubilized in lysis buffer $(20 \mathrm{mM}$ Tris at $\mathrm{pH}$ 6.2, 1\% SDS, $1 \mathrm{mM}$ EDTA, $1 \mathrm{mM}$ PMSF), and immediately boiled at $100^{\circ} \mathrm{C}$ for $3 \mathrm{~min}$. We loaded proteins on an $8 \%$ polyacrylamide SDS gel. The gel was transferred to PVDF membrane and blots were processed as described previously (Harlow and Lane 1988). We performed Western blotting by incubating the blots overnight with the first antibody, washing them four times with TBS-T, and incubating them for $1 \mathrm{~h}$ with the secondary antibody. After washing four times with TBS-T, the bound antibody was detected with an ECL Western blotting kit (Amersham Pharmacia Biotech).

Cells overexpressing GST and FbxA:GST were harvested at various developmental stages as indicated. A total of $2 \times 107$ cells were lysed on ice in $1 \mathrm{~mL}$ of NP-40 buffer ( $1 \times$ PBS, $1 \%$ Nonidet P-40, $10 \mathrm{mM} \mathrm{NaF}, 2 \mathrm{mM}$ EDTA, $1 \mathrm{mM}$ sodium pyrophosphate, $0.8 \mu \mathrm{g} / \mathrm{mL}$ leupeptin and $4 \mathrm{~g} / \mathrm{mL}$ aprotinin at $\mathrm{pH} 7.2$ ) for $5 \mathrm{~min}$. Samples were centrifuged at $15,000 \mathrm{rpm}$ for $10 \mathrm{~min}$. We incubated the supernatant with $80 \mu \mathrm{L}$ of GST beads (glutathione-Sepharose 4B, purchased from Amersham Pharmacia Biotech) for $1 \mathrm{~h}$ at $4^{\circ} \mathrm{C}$ with gentle rocking. The beads were washed with NP-40-containing lysis buffer three times and with $1 \times$ PBS twice, and the fusion protein was eluted from the beads by boiling in $1 \times$ SDS sample buffer. We performed Western blotting in these samples as described above.

The RegA antibody was a gift from David Traynor and Rob Kay, Medical Research Council, Cambridge, UK. The PKA-R and PKAcat antibodies were kindly provided by Michel Veron from Unité de Biochimie Cellulaire, Institut Pasteur, Paris.

Anti-human cullin 1 (Cul-1) antibody was purchased from Zymed Laboratories, Inc. The antibody is made against 11 amino acids and a synthetic peptide derived from the extreme carboxyl terminus of human Cullin1 protein. The peptide sequence is identical to that of Drosophila cullin1 in 9/11 positions and in 7/11 residues with cullins from C. elegans and CulA from Dictyostelium discoideum. Anti-GST antibody was purchased from Amersham Pharmacia Biotech.

Video imaging and chemotaxis assays

The chemotaxis assays and video imaging were performed as described previously (Ma et al. 1997; Meili et al. 1999).

\section{Acknowledgments}

We are indebted to Peter Thomason and Rob Kay for the antiRegA antibodies. We thank Negin Iranfar and Anson Nomura for technical assistance. We thank Sean Buchanan and Jennifer Roth for critical reading of the manuscript and members of the Firtel laboratory for helpful suggestions during this work. This work was supported by research grants from the United States Public Health Service to R.A.F.

The publication costs of this article were defrayed in part by payment of page charges. This article must therefore be hereby marked "advertisement" in accordance with 18 USC section 1734 solely to indicate this fact.

\section{Note added in proof}

As expected from our model and results with culA null cells described in Figure 7, addition of cAMP to developmentally competent culA or erk2 null cells constitutively expressing the PKA catalytic subunit does not cause a cAMP-dependent loss of RegA protein. This further supports a role for Erk2 in controlling the developmental decrease in RegA protein levels.

\section{References}

Abe, T., Early, A., Siegert, F., Weijer, C., and Williams, J. 1994. Patterns of cell movement within the Dictyostelium slug revealed by cell type-specific, surface labeling of living cells. Cell 77: 687-699.

Aubry, L. and Firtel, R.A. 1998. Spalten, a protein containing Galpha-protein-like and PP2C domains, is essential for celltype differentiation in Dictyostelium. Genes \& Dev. 12: $1525-1538$.

-1999. Integration of signaling networks that regulate Dictyostelium differentiation. Annu. Rev. Cell Dev. Biol. 15: 469-517.

Aubry, L., Maeda, M., Insall, R., Devreotes, P.N., and Firtel, R.A. 1997. The Dictyostelium mitogen-activated protein kinase ERK2 is regulated by ras and cAMP-dependent protein kinase (PKA) and mediates PKA function. J. Biol. Chem. 272: 3883-3886.

Bai, C., Sen, P., Hofmann, K., Ma, L., Goebl, M., Harper, J.W., and Elledge, S.J. 1996. SKP1 connects cell cycle regulators to the ubiquitin proteolysis machinery through a novel motif, the F-box. Cell 86: 263-74.

Balint-Kurti, P., Ginsburg, G., Rivero-Lezcano, O., and Kimmel, A.R. 1997. rZIP, a RING-leucine zipper protein that regulates cell fate determination during Dictyostelium development. Development 124: 1203-1213.

Chen, Z.J., Parent, L., and Maniatis, T. 1996. Site-specific phosphorylation of IkappaBalpha by a novel ubiquitination-dependent protein kinase activity. Cell 84: 853-862.

Chung, C.Y., Reddy, T.B.K., Zhou, K.M., and Firtel, R.A. 1998. A novel, putative MEK kinase controls developmental timing and spatial patterning in Dictyostelium and is regulated by ubiquitin-mediated protein degradation. Genes \& Dev. 12: 3564-3578.

Clark, A., Nomura, A., Mohanty, S., and Firtel, R.A. 1997. A ubiquitin-conjugating enzyme is essential for developmental transitions in Dictyostelium. Mol. Biol. Cell 8: 1989-2002.

Clow, P.A., Chen, T., Chisholm, R.L., and McNally, J.G. 2000. Three-dimensional in vivo analysis of Dictyostelium mounds reveals directional sorting of prestalk cells and defines a role for the myosin II regulatory light chain in prestalk cell sorting and tip protrusion. Development 127: 2715-2728.

Dealy, M.J., Nguyen, K.V., Lo, J., Gstaiger, M., Krek, W., Elson, D., Arbeit, J., Kipreos, E.T., and Johnson, R.S. 1999. Loss of Cull results in early embryonic lethality and dysregulation of cyclin E. Nature Genet. 23: 245-248.

Deshaies, R.J. 1999. SCF and Cullin/Ring H2-based ubiquitin ligases. Annu. Rev. Cell Dev. Biol. 15: 435-467.

Dynes, J.L., Clark, A.M., Shaulsky, G., Kuspa, A., Loomis, W.F., and Firtel, R.A. 1994. LagC is required for cell-cell interactions that are essential for cell-type differentiation in Dictyostelium. Genes \& Dev. 8: 948-958.

Ennis, H.L., Dao, D.N., Pukatzki, S.U., and Kessin, R.H. 2000. Dictyostelium amoebae lacking an F-box protein form spores rather than stalk in chimeras with wild type. Proc. Nat1. Acad. Sci. 97: 3292-3297.

Feldman, R., Correll, C., Kaplan, K., and Deshaies, R. 1997. A complex of Cdc4p, Skplp, and Cdc53p/cullin catalyzes ubiquitination of the phosphorylated CDK inhibitor Sic1p. Cell 
91: 221-230.

Galan, J.M. and Peter, M. 1999. Ubiquitin-dependent degradation of multiple F-box proteins by an autocatalytic mechanism. Proc. Natl. Acad. Sci. 96: 9124-9129.

Gaskins, C., Clark, A.M., Aubry, L., Segall, J.E., and Firtel, R.A. 1996. The Dictyostelium MAP kinase ERK2 regulates multiple, independent developmental pathways. Genes \& Dev. 10: $118-128$.

Hammerschmidt, M., Brook, A., and McMahon, A. 1997. The world according to hedgehog. Trends Genet. 13: 14-21.

Harlow, E. and Lane, D. 1988. Antibodies: A laboratory manual. Cold Spring Harbor Laboratory Press, Cold Spring Harbor, NY.

Heasman, J. 1997. Patterning in the Xenopus blastula. Development 124: 4179-4191.

Hegde, A., Inokuchi, K., Pei, W., Casadio, A., Ghirardi, M., Chain, D., Martin, K., Kandel, E., and Schwartz, J. 1997. Ubiquitin C-terminal hydrolase is an immediate-early gene essential for long-term facilitation in Aplysia. Cell 89: 115126.

Hopper, N.A., Anjard, C., Reymond, C.D., and Williams, J.G. 1993a. Induction of terminal differentiation of Dictyostelium by cAMP-dependent protein kinase and opposing effects of intracellular and extracellular cAMP on stalk cell differentiation. Development 119: 147-154.

Hopper, N.A., Harwood, A.J., Bouzid, S., Veron, M., and Williams, J.G. 1993b. Activation of the prespore and spore cell pathway of Dictyostelium differentiation by cAMP-dependent protein kinase and evidence for its upstream regulation by ammonia. EMBO J. 12: 2459-2466.

Horn, F. and Gross, J.D. 1996. Cyclic AMP dependent protein kinase and prestalk-cell expression in Dictyostelium. FEMS Microbiol. Lett. 137: 275-278.

Insall, R.H., Soede, R.D.M., Schaap, P., and Devreotes, P.N. 1994. Two cAMP receptors activate common signaling pathways in Dictyostelium. Mol. Biol. Cell 5: 703-711.

Jermyn, K.A., Duffy, K.T., and Williams, J.G. 1989. A new anatomy of the prestalk zone in Dictyostelium. Nature 340: $144-146$.

Jermyn, K., Traynor, D., and Williams. J. 1996. The initiation of basal disc formation in Dictyostelium discoideum is an early event in culmination. Development 122: 753-760.

Jiang, J. and Struhl, G. 1996. Complementary and mutually exclusive activities of decapentaplegic and wingless organize axial patterning during Drosophila leg development. Cell 86: 401-409.

Karin, M. and Ben-Neriah, Y. 2000. Phosphorylation meets ubiquitination: The control of NF-[kappa]B activity. Annu. Rev. Immunol. 18: 621-663.

Karin, M. and M. Delhase. 2000. The I kappa B kinase (IKK) and NF-kappa B: Key elements of proinflammatory signalling. Seminars in Immunology 12: 85-98.

Kellerman, K.A. and McNally. J.G. 1999. Mound-cell movement and morphogenesis in Dictyostelium. Dev. Biol. 208: 416-429.

Kiproes, E., Lander, L., Wing, J., He, W., and Hedgecock, E. 1996. cul-1 is required for cell cycle exit in C. elegans and identifies a novel gene family. Cell 85: 829-839.

Krek, W. 1998. Proteolysis and the G1-S transition: The SCF connection. Curr. Opin. Genet. Dev. 8: : 36-42.

Kuspa, A. and. Loomis, W.F 1992. Tagging developmental genes in Dictyostelium by restriction enzyme-mediated integration of plasmid DNA. Proc. Natl. Acad. Sci. 89: 8803-8807.

Lee, S., Escalante, R., and Firtel, R.A. 1997. A Ras GAP is essential for cytokinesis and spatial patterning in Dictyostelium. Development 124: 983-996.
Listzwan, J., Marti, A., Sutterluty, H., Gstaiger, M., Wirbelauer, C., and Krek, W. 1998. Association of human CUL-1 and ubiquitin-conjugating enzyme CDC34 with the F-box protein p45(SKP2): Evidence for evolutionary conservation in the subunit composition of the CDC34-SCK pathway. EMBO T. 15: 368-383.

Loomis, W., Shaulsky, G., and Wang, N. 1997. Histidine kinases in signal transduction pathways of eukaryotes. J. Cell. Sci. 110: 1141-1145.

Loomis, W.F. 1998. Role of PKA in the timing of developmental events in Dictyostelium cells. Microbiol. Mol. Biol. Rev. 62: 684 .

Loomis, W.F., Kuspa, A., and Shaulsky, G. 1998. Two-component signal transduction systems in eukaryotic microorganisms. Curr. Opin. Microbiol. 1: 643-648.

Lyapina, S.A., Correll, C.C., Kipreos, E.T., and Deshaies, R.J. 1998. Human CUL1 forms an evolutionarily conserved ubiquitin ligase complex (SCF) with SKP1 and an F-box protein. Proc. Nat. Acad. Sci.95: 7451-7456.

Ma, H., Gamper, M., Parent, C., and Firtel, R.A. 1997. The Dictyostelium MAP kinase kinase DdMEK1 regulates chemotaxis and is essential for chemoattractant-mediated activation of guanylyl cyclase. EMBO J. 16: 4317-4332.

Maeda, M., Aubry, L., Insall, R., Gaskins, C., Devreotes, P.N., and Firtel, R.A. 1996. Seven helix chemoattractant receptors transiently stimulate mitogen-activated protein kinase in Dictyostelium - Role of heterotrimeric G proteins. J. Biol. Chem. 271: 3351-3354.

Maniatis, T. 1999. A ubiquitin ligase complex essential for the NF-kappaB, Wnt/Wingless, and Hedgehog signaling pathways. Genes \& Dev. 13: 505-510.

Mann, S.K.O., Brown, J.M., Briscoe, C., Parent, C., Pitt, G., Devreotes, P.N., and Firtel, R.A. 1997. Role of cAMP-dependent protein kinase in controlling aggregation and postaggregative development in Dictyostelium. Dev. Biol. 183: 208221.

Mann, S.K.O., Devreotes, P.N., Eliott, S., Jermyn, K., Kuspa, A., Fechheimer, M., Furukawa, R., Parent, C.A., Segall, J., Shaulsky, G., et al., 1998. Cell biological, molecular genetic, and biochemical methods to examine Dictyostelium. In Cell biology - A laboratory handbook (ed. J.E. Celis), pp. 431-465. Academic Press, San Diego, CA.Mann, S.K.O. and Firtel, R.A. 1991. A developmentally regulated, putative serine/ threonine protein kinase is essential for development in Dictyostelium. Mech. Dev. 35: 89-101.

1993. cAMP-dependent protein kinase differentially regulates prestalk and prespore differentiation during Dictyostelium development. Development 119: 135-146.

Mann, S.K.O., Pinko, C., and Firtel, R.A. 1988. cAMP regulation on early gene expression in signal transduction mutants of Dictyostelium. Dev. Biol. 130: 294-303.

Mathias, N., Johnson, S.L., Winey, M., Adams, A.E., Goetsch, L., Pringle, J.R., Byers, B., and Goebl, M.G. 1996. Cdc53p acts in concert with Cdc4p and Cdc34p to control the G1-to-Sphase transition and identifies a conserved family of proteins. Mol. Cell. Biol. 16: 6634-6643.

Mehdy, M.C. and Firtel, R.A. 1985. A secreted factor and cyclic AMP jointly regulate cell-type-specific gene expression in Dictyostelium discoideum. Mol. Cell. Biol. 5: 705-713.

Meili, R., Ellsworth, C., Lee, S., Reddy, T.B.K., Ma, H., and Firtel, R.A. 1999. Chemoattractant-mediated transient activation and membrane localization of Akt/PKB is required for efficient chemotaxis to cAMP in Dictyostelium. EMBO J. 18: 2092-2105.

Meima, M.E. and Schaap, P. 1999. Fingerprinting of adenylyl cyclase activities during Dictyostelium development indi- 
cates a dominant role for adenylyl cyclase B in terminal differentiation. Dev. Biol. 212: 182-190.

Nelson, M.K., Clark, A., Abe, T., Nomura, A., Yadava, N., Funair, C.J., Jermyn, K.A., Mohanty, S., Firtel, R.A., and Williams, J.G. 2000. An F-Box/WD40 repeat-containing protein important for Dictyostelium cell-type proportioning, slug behaviour, and culmination. Dev. Biol. 224: 42-59.

Noegel, A., Gerisch, G., Stadler, J., and Westphal, M. 1986. Complete sequence and transcript regulation of a cell adhesion protein from aggregating Dictyostelium cells. EMBO $J$. 5: 1473-1476.

Nusse, R. 1997. A versatile transcriptional effector of Wingless signaling. Cell 89: 321-323.

Ohlmeyer, J. and Kalderon, D. 1997. Dual pathways for induction of wingless expression by protein kinase A and Hedgehog in Drosophila embryos. Genes \& Dev. 11: 2250-2258.

Patton, E., Willems, A., Sa, D., Kuras, L., Thomas, D., Craig, K., and Tyers, M. 1998. Cdc53 is a scaffold protein for multiple Cdc34/Skp1/F-box protein complexes that regulate cell division and methionine biosynthesis in yeast. Genes \& Dev. 12: 692-705.

Perrimon, N. 1996. Serpentine proteins slither into the Wingless and Hedgehog fields. Cell 86: 513-516.

Pitt, G.S., Milona, N., Borleis, J., Lin, K.C., Reed, R.R., and Devreotes, P.N. 1992. Structurally distinct and stage-specific adenylyl cyclase genes play different roles in Dictyostelium development. Cell 69: 305-315.

Raper, K.B. 1939. Influence of culture conditions upon the growth and development of Dictyostelium discoideum. I. Agr. Res. 58: 157-198.

Reymond, C.D., Schaap, P., Veron, M., and Williams, J.G. 1995. Dual role of cAMP during Dictyostelium development. Experientia 51: 1166-1174.

Rietdorf, J., Siegert, F., and Weijer, C.J. 1996. Analysis of optical density wave propagation and cell movement during mound formation in Dictyostelium discoideum. Dev. Biol. 177: 427-438.

Schnitzler, G.R., Briscoe, C., Brown, J.M., and Firtel, R.A. 1995. Serpentine cAMP receptors may act through a $G$ proteinindependent pathway to induce postaggregative development in Dictyostelium. Cell 81: 737-745.

Schulkes, C. and Schaap, P. 1995. cAMP-dependent protein kinase activity is essential for preaggregative gene expression in Dictyostelium. FEBS Lett. 368: 381-384.

Segall, J.E., Kuspa, A., Shaulsky, G., Ecke, M., Maeda, M., Gaskins, C., and Firtel, R.A. 1995. A MAP kinase necessary for receptor-mediated activation of adenylyl cyclase in Dictyostelium. J. Cell Biol. 128: 405-413.

Shaulsky, G., Escalante, R., and Loomis, W.F. 1996. Developmental signal transduction pathways uncovered by genetic suppressors. Proc. Natl. Acad. Sci. 93: 15260-15265.

Shaulsky, G., Fuller, D., and Loomis, W.F. 1998. A cAMP-phosphodiesterase controls PKA-dependent differentiation. Development 125: 691-699.

Simon, M.N., Pelegrini, O., Veron, M., and Kay, R.R. 1992. Mutation of protein kinase-A causes heterochronic development of Dictyostelium. Nature 356: 171-172.

Singleton, C.K., Zinda, M.J., Mykytka, B., and Yang, P. 1998. The histidine kinase dhkC regulates the choice between migrating slugs and terminal differentiation in Dictyostelium discoideum. Dev. Biol. 203: 345-357.

Sukumaran, S., Brown, J.M., Firtel, R.A., and McNally, J.G. 1998. lagC-null and gbf-null cells define key steps in the morphogenesis of Dictyostelium mounds. Dev. Biol. 200: $16-26$

Sutoh, K. 1993. A transformation vector for Dictyostelium dis- coideum with a new selectable marker Bsr. Plasmid 30: 150154.

Thomason, P.A., Traynor, D., Cavet, G., Chang, W.T., Harwood, A.J., and Kay, R.R. 1998. An intersection of the cAMP/ PKA and two-component signal transduction systems in Dictyostelium. EMBO J. 17: 2838-2845.

Thomason, P., Traynor, D., and Kay, R. 1999a. Taking the plunge - terminal differentiation in Dictyostelium. Trends Genet. 15: 15-19.

Thomason, P.A., Traynor, D., Stock, J.B., and Kay, R.R. 1999b. The RdeA-RegA system, a eukaryotic phospho-relay controlling cAMP breakdown. J. Biol. Chem. 274: 27379-27384.

Toda, T., Ochotorena, I., and Kominami, K. 1999. Two distinct ubiquitin-proteolysis pathways in the fission yeast cell cycle. Phil. Trans. Royal Soc. London. Series B: Biol. Sci. 354: 1551-1557.

Tyers, M. and Jorgensen, P. 2000. Proteolysis and the cell cycle: With this RING I do thee destroy. Curr. Opin. Genet. Dev. 10: $54-64$.

Verma, R. and Deshaies, R.J. 2000. A proteasome howdunit: The case of the missing signal. Cell 101: 341-344.

Wang, B. and Kuspa, A. 1998. Dictyostelium development in the absence of cAMP. Science 277: 251-254.

Wang, N., Soderbom, F., Anjard, C., Shaulsky, G., and Loomis, W.F. 1999a. SDF-2 induction of terminal differentiation in Dictyostelium discoideum is mediated by the membranespanning sensor kinase DhkA. Mol. Cell. Biol. 19:47504756.

Wang, Y., Penfold, S., Tang, X., Hattori, N., Riley, P., Harper, J.W., Cross, J.C., and Tyers, M. 1999b. Deletion of the Cull gene in mice causes arrest in early embryogenesis and accumulation of cyclin E. Curr. Biol. 9: 1191-1194.

Wessels, D.J., Zhang, H., Reynolds, J., Daniels, K., Heid, P., Lu, S., Kuspa, A., Shaulsky, G., Loomis, W.F., and Soll, D.R. 2000. The internal phosphodiesterase RegA is essential for the suppression of lateral pseudopods during Dictyostelium chemotaxis. Mol. Biol. Cell 11: 2803-2820.

Willems, A., Lanker, S., Patton, E., Craig, K., Nason, T., Mathias, N., Kobayashi, R., Wittenberg, C., and Tyers, M. 1996. Cdc52 targets phosphorylated G1 cyclincs for degradation by the ubiquitin proteolytic pathway. Cell 86: 453-463.

Willems, A.R., Goh, T., Taylor, L., Chernushevich, I., Shevchenko, A., and Tyers, M. 1999. SCF ubiquitin protein ligases and phosphorylation-dependent proteolysis. Phil. Trans. Royal Soc. London. Series B: Biol. Sci. 354: 15331550.

Zhukovskaya, N., Early, A., Kawata, T., Abe, T., and Williams, J. 1996. cAMP-dependent protein kinase is required for the expression of a gene specifically expressed in Dictyostelium prestalk cells. Dev. Biol. 179: 27-40. 


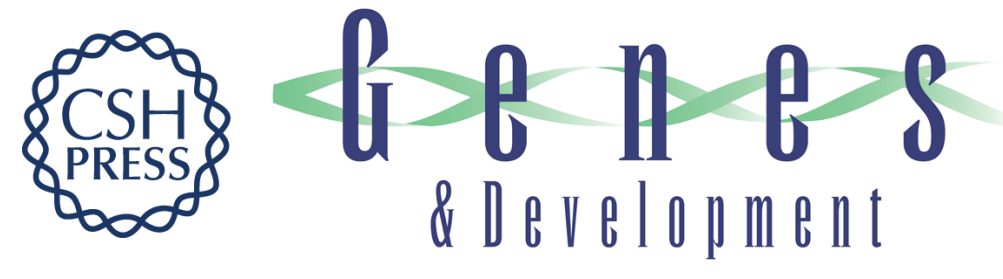

\section{Regulated protein degradation controls PKA function and cell-type differentiation in Dictyostelium}

Sudhasri Mohanty, Susan Lee, Nagendra Yadava, et al.

Genes Dev. 2001, 15:

Access the most recent version at doi:10.1101/gad.871101

References This article cites 82 articles, 36 of which can be accessed free at: http://genesdev.cshlp.org/content/15/11/1435.full.html\#ref-list-1

License

Email Alerting

Receive free email alerts when new articles cite this article - sign up in the box at the top Service right corner of the article or click here.

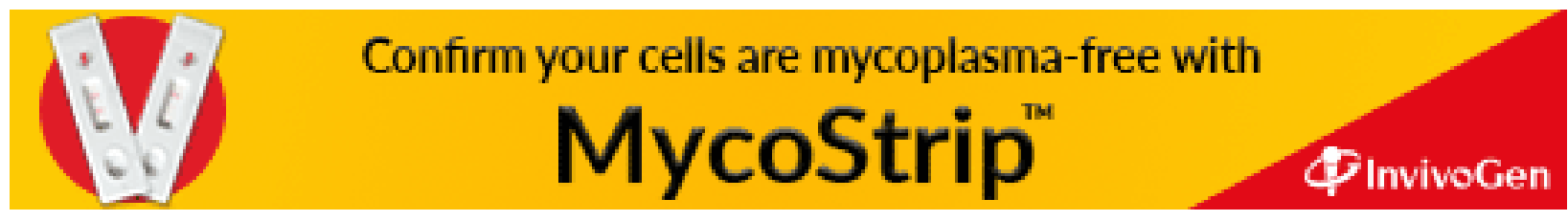

